\title{
Continuous transversus abdominis plane block
}

\section{vs intermittent bolus for analgesia after abdominal surgery: a randomized trial}

This article was published in the following Dove Press journal:

Journal of Pain Research

18 July 2017

Number of times this article has been viewed

\author{
Vasanth Rao Kadam' \\ Roelof M Van Wijk' \\ John L Moran² \\ Shantan Ganesh ${ }^{3}$ \\ A Kumar' \\ Rajesh Sethi' \\ Patricia Williams ${ }^{2,4}$ \\ 'Department of Anaesthesia, The \\ Queen Elizabeth Hospital, School \\ of Medicine, University of Adelaide, \\ Adelaide, SA, ${ }^{2}$ Intensive Care Unit, \\ The Queen Elizabeth Hospital, School \\ of Medicine, University of Adelaide, \\ Adelaide, SA, ${ }^{3}$ Department of Surgery, \\ The Queen Elizabeth Hospital, \\ School of Medicine, University of \\ Adelaide, Adelaide, SA, ${ }^{4}$ Department \\ of Epidemiology and Preventive \\ Medicine, School Public Health and \\ Preventive Medicine, Australian \\ and New Zealand Intensive Care \\ Research Centre, Monash University, \\ Melbourne, VIC, Australia
}

Correspondence: Vasanth Rao Kadam Department of Anaesthesia, The Queen Elizabeth Hospital, 28 Woodville Rd,

Woodville, SA 50II, Australia

$\mathrm{Tel}+6$ I 882226000

Fax +6I 882227065

Email vasanth.rao@.sa.gov.au
Background: Continuous and intermittent bolus techniques of transversus abdominis plane (TAP) blocks have been used for analgesia after abdominal surgery. Although both are effective, there are no studies comparing them. The aim of this study is to compare analgesia and cost-effectiveness between these groups.

Methods: After obtaining ethical approval, 20 American Society of Anesthesiologists ASA grade I to III patients undergoing elective abdominal surgery were recruited with 10 patients allocated to each arm. Bilateral ultrasound-guided TAP blocks were performed with an initial bolus of $0.5 \%$ ropivacaine $20 \mathrm{~mL}$ per side, followed by catheter insertion. After surgery, the continuous infusion group received $0.2 \%$ ropivacaine $8 \mathrm{~mL} /$ hour on each side and the intermittent bolus group received doses of $0.2 \%$ ropivacaine $20 \mathrm{~mL}$ per side every 8 hours for 48 hours. Both groups received intravenous fentanyl patient-controlled analgesia and regular oral paracetamol. Parameters recorded included numerical rating scores for pain and post-operative analgesic consumption at baseline (time 0 ) and at 1 hour, 1 day and 2 days post-operatively. The duration of catheter insertion, complications, patient satisfaction and information regarding costs were also recorded. Patient satisfaction was assessed utilizing a 4-point "Likert" scale on day 2 and on day 30. Pain and Likert scores were analysed by non-parametric sum rank test and all two-sampled $t$-tests assumed unequal variances.

Results: There was no difference between duration of TAP block, anesthetic and surgical technique and length of stay ( $p=0.23$ ). Primary outcomes: pain scores at rest and cough were not significantly different $(p=0.20)$ between the groups. Satisfaction scores were similar at day 2 and 30 ( $p=0.77$ ). However, the bolus group was more cost-effective (AU\$347.98 vs AU\$429.43).

Conclusion: Continuous or bolus TAP blocks are effective analgesic techniques in abdominal surgery, with bolus technique being more economical.

Keywords: transversus abdominis plane block, postoperative pain, continuous catheter, bolus dosing

\section{Introduction}

In recent years, continuous transversus abdominis plane (TAP) block has been used to obtain post-operative analgesia after abdominal surgery. ${ }^{1-6}$ Even continuous wound infiltration could be effective as an active alternative and non-inferior to epidural analgesia in hepato-pancreato-biliary surgery. ${ }^{7}$ A case series on TAP intermittent bolus technique showed benefits of reduced pain scores and analgesia; however, no comparison was undertaken with other techniques. ${ }^{8}$ Another case series showed opioid sparing potential of TAP catheters. ${ }^{9}$ The same author described in another randomized trial that TAP catheter local anesthetic by intermittent boluses compared with epidural had no significant difference in pain scores. ${ }^{10}$ Another retrospective study on continuous TAP 
catheter in renal transplant patients found reduced opioid consumption. ${ }^{1}$ Although TAP block has been shown to be effective in both continuous and bolus techniques, no studies have been published comparing continuous TAP block with the intermittent bolus method. The aim of this study was to compare pain scores; opioid consumption, and cost differences between the groups.

\section{Materials and methods}

Human Research Ethics Committee approval was obtained (reference number HREC/14/TQEHLMH/116) and this trial was registered prospectively with the Australian and New Zealand Clinical Trial Registry reference no: ACTRN12614000639628. The study was designed to recruit 20 patients; 10 in each arm of the study. This was a single center trial conducted at The Queen Elizabeth Hospital with main flow of patients from the colorectal division of surgery during December 2014 to November 2015. Patients having elective abdominal surgery with midline incision between 18 and 85 years of age, with ASA less than grade $<4$ and adequate English language skills were included after obtaining informed consent. Enrolment was done in pre-admission clinic by the anesthetist. Exclusion criteria were emergency surgery, allergy to local anesthetic, pregnancy, chronic opioid medication, mental handicap, or psychiatric condition precluding adequate communication.

There were no parallel active trials in the literature to draw sample size estimation for comparing TAP continuous to bolus dosing. Due to time and resources available, 20 patients were considered. Randomization was done by the statistician with a simple randomization table created by using the "ralloc" user written command in Stata ${ }^{\mathrm{TM}}$ statistical software. ${ }^{11}$ Numbered and sealed opaque envelopes were created containing the group allocation. On arrival in holding bay, the chief investigator handed the box of envelopes to the attending nurse or colleague to assign participants for intervention. This was a single (patient) blinded study, where the patients would only become aware of their allocation once they arrived on the ward at the time of the 8-hour bolus.

During the surgical procedure, patients had a standard general anesthetic technique using propofol, rocuronium and sevoflurane with air and $\mathrm{O}_{2}$ with routine monitoring. Intermittent doses of IV fentanyl were used to provide intraoperative analgesia. In both groups, post-operatively, prior to extubation, bilateral posterior TAP catheters were placed by the primary investigator under ultrasound guidance by placing the probe in the midaxillary line. A $15-6 \mathrm{MHz}$ Linear Probe(Sonosite X-Porte, SonoSite Inc. Bothell, WA,
USA) was used, to locate the TAP plane with a 18 gauge Tuohy needle. Subsequently, a bolus dose of $20 \mathrm{~mL}$ of $0.5 \%$ ropivacaine (Naropin, AstraZeneca Pty Ltd, Sydney, NSW, Australia) was given followed by catheter insertion. Catheter patency was tested by injecting saline and position of the catheter by ultrasound. In the post anesthetic care unit (PACU), an infusion of ropivacaine $0.2 \% 8 \mathrm{~mL} / \mathrm{h}$ was administered via each catheter for 2 days in the continuous infusion group (CIG) by infusion syringe driver Terumo TE 311 (Terumo Corporation, Tokyo Japan), whereas in the intermittent bolus group (IBG) a bolus dose of $20 \mathrm{~mL} 0.2 \%$ ropivacaine was administered 8 hourly via each catheter by Acute Pain Service (APS) personnel. The rationale of infusion rate was based on our previous study on TAP catheter local anesthetic infusion. ${ }^{5}$ Patients in both groups were provided with paracetamol $1 \mathrm{~g}$ QID (orally or IV) and a fentanyl patient-controlled-analgesia (PCA) device (bolus 10 to $40 \mu \mathrm{g}$; lockout time 5 minutes; no background infusion) as part of a multimodal analgesic approach. Patients aged $>70$ years were offered initial bolus of $10 \mu \mathrm{g}$ and $<70$ years $20 \mu \mathrm{g}$, this could be increased to 40 $\mu \mathrm{g}$ based on pain score assessments by ward nursing staff. Any further change needed authorization by the APS.

The primary outcomes measured were: Numerical Rating Scores for Pain (NRS-P; 0-10) and analgesics used in PACU at 0,1 hour, day 1 and 2. The PACU pain scores were assessed by the recovery nursing staff. The APS team was not blinded as it was not possible to do catheter care without knowing it. The APS team independently recorded the pain scores and analgesics used in the postoperative ward on day 1 and 2 . Dermatomal assessment for sensory block for temperature was confirmed by using ice pack bilaterally. Procedure related complications or technical issues, duration of introduction of catheter(s), and material costs were also noted. A 4-point "Likert"-scale (1-2-3-4) was used on day 2 and during a follow-up telephone call at 1 month to assess patient satisfaction with the analgesic technique used. Discharge times were obtained through the hospital information system.

All results were recorded on a data collection sheet and subsequently entered in a protected database. Continuous variables were analyzed by two-sampled $t$-test assuming unequal variance; categorical variables by the Fisher exact test. The distributional forms of pain and Likert scores at different time points were initially examined using summary statistics (including the higher moments of kurtosis and skewness) and kernel density plots ( $\cong$ smoothed histograms). In the absence of approximation to the normal distribution, treatment group differences for pain and Likert scores were analyzed by non-parametric rank-sum tests. 


\section{Results}

All patients completed the trial and none were lost to follow up (see consort flow diagram Figure 1). There were no difference between the groups in demographics (age, sex), duration of TAP catheter procedure, anesthesia and surgical procedures, incision length and length of stay (Table 1). The first primary outcome measure of pain scores at cough and rest was not significantly different between the groups for any of the time intervals assessed. The second primary outcome of IV PCA fentanyl use was significantly less in the intermittent bolus group in PACU ( $p=0.02)$, although no differences in IV fentanyl PCA usage were noted between study groups on postoperative days 1 or 2 (Table 2). As pain and Likert score distributions did not approximate a normal distribution, the treatment group differences were computed using the rank-sum test. Between the groups, the pain scores at rest and cough were not significantly different (Table 3). The satisfaction scores had similar results for day 2 and 30 . In the IBG, there was one dose delayed, one dose missed and one patient was noted to have catheter in the intravascular space after aspiration on day 1 without any issues. This catheter was withdrawn to $2 \mathrm{~cm}$ and subsequent bolus was continued with adequate block. No patients had any serious adverse events.

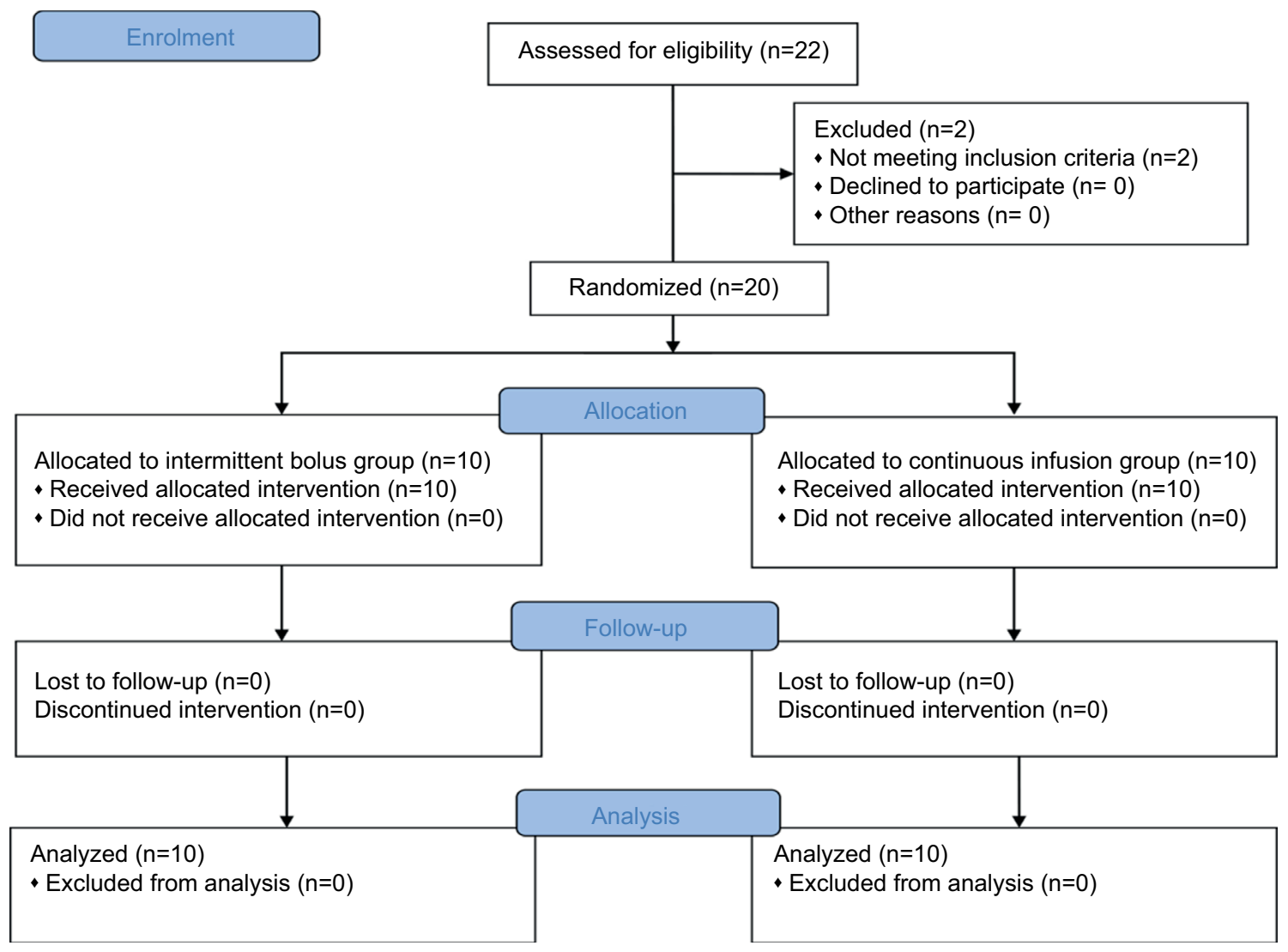

Figure I Consort flow diagram

Table I Demographic data and the duration of the procedures

\begin{tabular}{|c|c|c|c|}
\hline Variables & Intermittent bolus group & Continuous infusion group & $p$-value \\
\hline Age (years) & $67.6 \pm 8.7$ & $60.7 \pm 15.24$ & 0.23 \\
\hline Gender M:F & $8: 2$ & $8: 2$ & 0.99 \\
\hline Incision length $(\mathrm{cm})$ & $22.95 \pm 6.27$ & $20.85 \pm 5.26$ & 0.43 \\
\hline Surgery duration (min) & $188.6 \pm 87.67$ & $149.4 \pm 49.74$ & 0.24 \\
\hline Anesthesia duration (min) & $207.4 \pm 85.96$ & $168.3 \pm 48.49$ & 0.23 \\
\hline TAP procedure duration (min) & $8.5 \pm 3.47$ & $9.7 \pm 5.034$ & 0.54 \\
\hline Length of stay (days) & $6.9 \pm 3.93$ & $6.9 \pm 2.18$ & 0.99 \\
\hline
\end{tabular}

Note: All variables are reported as mean $\pm S D$.

Abbreviations: TAP, transversus abdominis plane; $M$, male; $F$, female. 
Table 2 Fentanyl use

\begin{tabular}{llll}
\hline & Intermittent bolus group & Continuous infusion group & p-value \\
\hline Fentanyl use PACU $(\mu \mathrm{g})$ & $142.8 \pm 93.40$ & $276.5 \pm 92.26$ & 0.02 \\
Fentanyl use day I $(\mu \mathrm{g})$ & $973 \pm 677.1$ & $1055.9 \pm 914.3$ & 0.82 \\
Fentanyl use day 2 $(\mu \mathrm{g})$ & $801.5 \pm 1034.9$ & $1085.5 \pm 1097.1$ & 0.56 \\
Total fentanyl used $(\mu \mathrm{g})$ & $1868.5 \pm 1543.467$ & $2455.5 \pm 1899.252$ & 0.46 \\
\hline
\end{tabular}

Note: All variables are reported as mean \pm SD.

Abbreviation: PACU, post anesthetic care unit.

Table 3 Pain and satisfaction scores

\begin{tabular}{|c|c|c|c|}
\hline Variables & Intermittent bolus group & Continuous infusion group & $p$-value \\
\hline \multicolumn{4}{|l|}{ PACU } \\
\hline Pain scores cough: 0 hour & $0(5) 8$ & $0(4.5) 9$ & 0.87 \\
\hline Pain scores cough: I hour & 0 (4) 8 & $2(6) 10$ & 0.20 \\
\hline \multicolumn{4}{|l|}{ Day I } \\
\hline Pain scores at rest & $0(3) 6$ & $0(4) 6$ & 0.99 \\
\hline Pain scores at cough & $0(6.5) 9$ & I (7) 10 & 0.62 \\
\hline \multicolumn{4}{|l|}{ Day 2} \\
\hline Pain scores at rest & $0(2) 5$ & $0(2) 4$ & 0.88 \\
\hline Pain scores at cough & $0(6.5) 10$ & $2(5.5) 10$ & 0.77 \\
\hline Likert score day 2 & I (2) 3 & I (2) 3 & 0.77 \\
\hline \multicolumn{4}{|l|}{ Day 30} \\
\hline Likert score day 30 & I (2) 3 & I (2) 4 & 0.97 \\
\hline
\end{tabular}

Note: All scores are reported as min (mean) and max.

Abbreviation: PACU, post anesthetic care unit.

On dermatomal block assessment, 3 patients in each group had no block or no block was documented. Despite no demonstrable block, these patients were not considered violating the protocol as they fulfilled other criteria. In the bolus group, on day 1 and 2, the dermatomal block ranged from T6-L1 bilaterally. In the continuous group on day 1, the dermatomal block ranged from T6-T12 followed by T8-L1 on day 2, with regression of two segments on day 2. In regard to complications (Table 4): two of the IBG patients reported pain starting at around 6 hours after the last bolus, with relief obtained immediately after the next dose. In the CIG, 1 patient had a leak around the right TAP catheter; this was adjusted by catheter withdrawal by $1 \mathrm{~cm}$ and applying a new dressing. Cost analysis revealed the total cost relating to consumables and patient care was less in the IBG compared with CIG (AU\$347.98 vs AU\$429.43) (Table S1-S3).

\section{Discussion}

Though there was no statistical difference in gender between the groups, both groups had slightly more male predominance, thus leaving the potential for intragroup bias. This most likely occurred simply by chance; a reflection of the known increased tendency of small number trials to generate treatment groups that are unbalanced with respect to prognostic factors. ${ }^{12}$ Based on the results, the first primary outcome measure on pain scores at cough and rest did not statistically differ between the groups. The second primary outcome on fentanyl use was significantly lower in the IBG in the PACU $(p=0.02)$. It appears that the IBG was comparable with the CIG in relation to pain scores. The most likely cause of this one significant finding on fentanyl use was chance, related to multiple statistical testing. Some of our results were similar to the results of the first TAP bolus study $;^{8}$ both groups having prolonged analgesia and reduced consumption of opioids. The secondary outcome measures showed that the patients appeared to be satisfied with either technique. The only important difference between the two techniques we could discern was in relation to costs. Even with medical personnel involved in administration of the IBG, this was still more cost-effective compared with the CIG. We realized that provider administered TAP catheter boluses every 8 hours are more labour intensive and it can be difficult to ensure the availability of providers at any time to deliver a bolus. Currently, we are working on a protocol allowing nursing staff to administer the intermittent bolus injections, thus improving availability and possibly further reducing cost. This will only occur after adequate training, and will include 20 minutes of hemodynamic monitoring after each bolus. In addition to lower cost, the patients receiving intermittent bolus injections have the advantage of not being attached to infusion devices enabling easier mobilization. This was not reflected in the discharge times, 
Table 4 Procedures and complications

\begin{tabular}{lll}
\hline Complications & Intermittent bolus group (n) & Continuous infusion group (n) \\
\hline Bowel resection & 9 & 8 \\
Other laparotomy & 1 & 2 \\
TAP block technical difficulty (poor image, & 3 & 3 \\
obesity, fibrosis) & & \\
Peritoneal puncture & $\mathrm{I}$ & 0 \\
Leaks & 0 & $\mathrm{I}$ \\
Vascular injection & $\mathrm{I}$ & 0 \\
Surgical complication (anastomotic leak) & 0 & $\mathrm{I}$ \\
lleus & 3 & 2 \\
Confusion & $\mathrm{I}$ & $\mathrm{I}$ \\
Delayed discharge (infection and wound breakdown) & 0 & 2 \\
\hline
\end{tabular}

Abbreviation: TAP, transversus abdominis plane.

but the study was likely underpowered to demonstrate any differences. The pragmatic approach of costing is to take the current market price of the item. It is important not to look only at the market price, but also at the time (and cost) expended by caregivers. The true marginal cost of the time may be valued higher or lower than the gross salaries paid per hour and is a standard way of measuring opportunity cost of physicians and nurses in health care economic evaluation. ${ }^{13}$ We do understand that over a 24 -hour period, the patients in the CIG would have received higher LA compared with the IBG, which may have impacted their pain score. In our observation in the IBG, two patients complained of pain occurring at around 6 hours after the 20 $\mathrm{mL} 0.2 \%$ ropivacaine bolus and reported immediate relief after the next bolus injection. We may need to consider a slightly higher frequency of bolus doses, with possibly a lower volume or an even lower concentration than $0.2 \%$ of ropivacaine in view of potential local anesthetic toxicity. In a previous study, an intraoperative $40 \mathrm{~mL}$ bolus dose of $0.5 \%$ ropivacaine did not show any toxicity issues. In this study, the mean $( \pm \mathrm{SD})$ peak plasma total (bound plus unbound) ROP concentration $\left(\mathrm{C}_{\max }\right)$ was $2.09( \pm 0.81) \mathrm{mg} / \mathrm{L}$ and unbound ropivacaine concentration was $0.044( \pm 0.016)$ $\mathrm{mg} / \mathrm{L} .{ }^{14} \mathrm{We}$ also realized that in the IBG, the 8-hourly visits by APS staff might have an additional placebo effect; thus leading to a performance bias.

Strengths: Our study had a randomized prospective design. It is the first study comparing intermittent bolus with continuous infusion TAP blocks. A comprehensive cost analysis is included.

Limitation: This was a small study and the chance of a $\beta$ error was high. The small numbers were due to local practice change in favor of the laparoscopic method and subsequent reduced number of open cases in the given period of time. Because of the setup, blinding was effectively limited to the recovery stage. The cost analysis was done for South Australia Health and this might vary from other institutions.

This small randomized trial report can provide the basis to plan larger studies, including placebo-controlled designs.

\section{Conclusion}

Both continuous and intermittent bolus TAP blocks were effective analgesic techniques after abdominal surgery. The intermittent bolus technique appeared to be more cost-effective, with the caveat of a relatively small sample size. However, the intermittent bolus technique was more labor intensive.

\section{Acknowledgments}

Emma Griffith, Lisa Jenkins and Kay Habel from the APS for the acquisition of all the data during the APS rounds on the ward.

Presented as an e-poster at the Australian and New Zealand College of Anaesthetists and Faculty of Pain Medicine 2016 Annual Scientific Meeting May 1-2, Auckland.

The Queen Elizabeth Hospital Department of Anaesthesia provided funding for this study.

\section{Author contributions}

VRK: Designing the study, ethics and clinical trial registry, recruitment, performance of the regional block, collection of data, co-ordination with authors and correspondence. RMVW: Designing the study, ethics approval, clinical trial registry, reviews of paper drafts and approval of final version. JLM: Statistical analysis, review of paper drafts and approval of final version. AK: Data collection, paper drafts and approval of final version. RS: Costing details on the technique, approval of final version. SG: Paper drafts and approval of final version. 
PW: Data entry, manuscript revision. All authors contributed toward data analysis, drafting and revising the paper and agree to be accountable for all aspects of the work.

\section{Disclosure}

The authors report no conflicts of interest in this work.

\section{References}

1. Farag E, Guirguis MN, Helou M, et al. Continuous transversus abdominis plane block catheter analgesia for postoperative pain control in renal transplant. J Anesth. 2015;29(1):4-8.

2. Hebbard PD, Barrington MJ, Vasey C. Ultrasound-guided continuous oblique subcostal transversus abdominis plane blockade: description of anatomy and clinical technique. Reg Anesth Pain Med. 2010;35(5):436-441.

3. Heil JW, Nakanote KA, Madison SJ, et al. Continuous transversus abdominis plane (TAP) blocks for postoperative pain control after hernia surgery: a randomized, triple-masked, placebo-controlled study. Pain Med. 2014;15(11):1957-1964.

4. Niraj G, Kelkar A, Hart E, Kaushik V, Fleet D, Jameson J. Four quadrant transversus abdominis plane block and continuous transversus abdominis plane analgesia: a 3-year prospective audit in 124 patients. $J$ Clin Anesth. 2015;27(7):579-584.

5. Kadam RV, Field JB. Ultrasound-guided continuous transverse abdominis plane block for abdominal surgery. J Anaesthesiol Clin Pharmacol. 2011;27(3):333-336.
6. Rao Kadam V, Van Wijk RM, Moran JI, Miller D. Epidural versus continuous transversus abdominis plane catheter technique for postoperative analgesia after abdominal surgery. Anaesth Intensive Care. 2013;41(4):476-481.

7. Mungroop TH, Veelo DP, Busch OR, et al. Continuous wound infiltration versus epidural analgesia after hepato-pancreato-biliary surgery (POP-UP): a randomised controlled, open-label, non-inferiority trial. Lancet Gastroenterol Hepatol. 2016;1(2):105-113.

8. Bjerregaard N, Nikolajsen L, Bendtsen TF, Rasmussen BS. Transversus abdominis plane catheter bolus analgesia after major abdominal surgery. Anesthesiol Res Pract. 2012;2012:596536.

9. Niraj G, Kelkar A, Fox AJ. Oblique sub-costal transversus abdominis plane (TAP) catheters: an alternative to epidural analgesia after upper abdominal surgery. Anaesthesia. 2009;64(10):1137-1140.

10. Niraj G, Kelkar A, Jeyapalan I, et al. Comparison of analgesic efficacy of subcostal transversus abdominis plane blocks with epidural analgesia following upper abdominal surgery. Anaesthesia. 2011;66(6): 465-471.

11. Ryan P. Ralloc - allocation of treatments in controlled trials using random permuted blocks. Stata Technical Bulletin. 1998;41:43-47.

12. Kernan WN, Viscoli CM, Makuch RW, Brass LM, Horwitz RI. Stratified randomization for clinical trials. J Clin Epidemiol 1999;52(1):19-26.

13. Drummond MF, Sculpher MJ, Torrance G, O'Brien BJ, Stoddart GL. Methods for the Economic Evaluation of Health Care Programmes. 3rd ed. Oxford (UK): Oxford University Press; 2005.

14. Kumar SK, Rao V, Morris RG, Watts RW, Westley IS. Ropivacaine (total and unbound) and AGP concentrations after transversus abdominis plane block for analgesia after abdominal surgery. Ther Drug Monit. 2014;36(6):759-764. 


\section{Supplementary materials}

Table SI Cost analysis (see detailed costing in Supplementary material)

\begin{tabular}{lll}
\hline Items & Intermittent bolus group & Continuous infusion group \\
\hline Intra-operative consumables and care & 166.69 & 166.69 \\
Postoperative consumables & 35.92 & 110.82 \\
Postoperative care (nursing/medical) & 145.37 & 151.92 \\
Total cost & 347.98 & 429.43 \\
\hline
\end{tabular}

Note: All costs in AU\$ (the costings are from South Australia Health).

Table S2 Intra-operative consumables and care

\begin{tabular}{|c|c|c|c|c|c|c|}
\hline \multirow[t]{2}{*}{ Consumables } & \multicolumn{3}{|c|}{ Intermittent bolus group } & \multicolumn{3}{|c|}{ Continuous infusion group } \\
\hline & Quantity & Unit cost (\$) & $\overline{C o s t}(\$)$ & Quantity & Unit cost (\$) & Cost (\$) \\
\hline Standard anesthetic tray & 1 & 23.68 & 23.68 & $\mathrm{I}$ & 23.68 & 23.68 \\
\hline Gloves & $\mathrm{I}$ & 1.40 & 1.40 & $\mathrm{I}$ & 1.40 & 1.40 \\
\hline Epidural kit $19 \mathrm{G}$ & I & 56.60 & 56.60 & I & 56.60 & 56.60 \\
\hline Ropivacaine I\% & 2 & 2.40 & 4.80 & 2 & 2.40 & 4.80 \\
\hline Skin prep swabs & 3 & 5.07 & 15.21 & 3 & 5.07 & $|5.2|$ \\
\hline Sterile gel (ultrasound) & I & 0.05 & 0.05 & I & 0.05 & 0.05 \\
\hline Sterile sheath (ultrasound) & 1 & 14.00 & 14.00 & $\mathrm{I}$ & 14.00 & 14.00 \\
\hline Subtotal & & & 115.74 & & & 115.74 \\
\hline Care & Duration (min) & Hourly rate (\$) & Cost (\$) & Duration (min) & Hourly rate (\$) & Cost (\$) \\
\hline Medical (hour) & 15 & 135.78 & 33.95 & 15 & 135.78 & 33.95 \\
\hline Nursing (hour) & 30 & 34.00 & 17.00 & 30 & 34.00 & 17.00 \\
\hline Subtotal & & & 50.95 & & & 50.95 \\
\hline
\end{tabular}

Note: All costs in AU\$.

Table S3 Postoperative consumables and care

\begin{tabular}{|c|c|c|c|c|c|c|c|c|}
\hline \multirow[t]{2}{*}{ Consumables } & \multicolumn{4}{|c|}{ Intermittent bolus group } & \multicolumn{4}{|c|}{ Continuous infusion group } \\
\hline & Quantity & & Unit price (\$) & Cost (\$) & Quantity & & Unit price (\$) & Cost (\$) \\
\hline $20 \mathrm{~mL}$ syringes & 12 & & 0.27 & 3.24 & NA & & NA & NA \\
\hline $50 \mathrm{~mL}$ syringes & NA & & NA & NA & 8 & & 0.48 & 3.84 \\
\hline $\begin{array}{l}0.2 \% \text { ropivacaine } \\
\text { (ampoules) }\end{array}$ & 12 & & 1.50 & 18.00 & NA & & NA & NA \\
\hline $\begin{array}{l}0.2 \% \text { ropivacaine } \\
\text { (polybag) }\end{array}$ & NA & & NA & NA & 4 & & 14.00 & 56.00 \\
\hline Rem Epi Set & NA & & NA & NA & 2 & & 15.95 & 31.90 \\
\hline Sterile gloves & 6 & & 1.40 & 8.40 & 8 & & 1.40 & 12.80 \\
\hline $\begin{array}{l}\text { Sterile gloves (for } \\
\text { catheter removal) }\end{array}$ & 2 & & 1.40 & 2.80 & 2 & & 1.40 & 2.80 \\
\hline $\begin{array}{l}\text { Gauze swabs (upon } \\
\text { removal) }\end{array}$ & 2 & & 0.37 & 0.74 & 2 & & 0.37 & 0.74 \\
\hline $\begin{array}{l}\text { IV } 3000 \text { dressing } \\
\text { (upon removal) }\end{array}$ & 2 & & 1.37 & 2.74 & 2 & & 1.37 & 2.74 \\
\hline Subtotal & & & & 35.92 & & & & 110.82 \\
\hline Care & Quantity & $\begin{array}{l}\text { Duration } \\
\text { (min) }\end{array}$ & $\begin{array}{l}\text { Hourly } \\
\text { rate }(\$)\end{array}$ & Cost (\$) & Quantity & $\begin{array}{l}\text { Duration } \\
\text { (min) }\end{array}$ & $\begin{array}{l}\text { Hourly } \\
\text { rate }(\$)\end{array}$ & Cost (\$) \\
\hline Medical (hours) & 6 & 15 & 46.27 & 69.41 & NA & NA & NA & NA \\
\hline Nursing (hours) & 24 & 5 & 37.98 & 75.96 & $\begin{array}{l}\text { Mon. } 32 \\
\text { Inf. } 8\end{array}$ & $\begin{array}{l}5 \\
10\end{array}$ & 37.98 & 151.92 \\
\hline Subtotal & & & & 145.37 & & & & 151.92 \\
\hline
\end{tabular}

Note: All costs in AU\$.

Abbreviations: Inf, change of infusion syringe; Mon, monitoring of patient; NA, not applicable. 
The Journal of Pain Research is an international, peer reviewed, open access, online journal that welcomes laboratory and clinical findings in the fields of pain research and the prevention and management of pain. Original research, reviews, symposium reports, hypothesis formation and commentaries are all considered for publication.
The manuscript management system is completely online and includes a very quick and fair peer-review system, which is all easy to use. Visit http://www.dovepress.com/testimonials.php to read real quotes from published authors. 